Philip J. Peyton

\section{Carbon dioxide elimination and cardiac output changes}

Accepted: 25 December 2012

Published online: 24 January 2013

(C) Springer-Verlag Berlin Heidelberg and ESICM 2013

Dear Editor,

I read with interest the paper by Monnet et al [1]. The authors found that changes in end-tidal carbon dioxide $\left(\mathrm{EtCO}_{2}\right)$ partial pressure more closely followed changes in cardiac index (CI) induced by passive leg raising than did concurrent changes in stroke volume estimated by the pulse contour method. Their findings are consistent with those recently found by García et al. [2] in ventilated intensive care patients with acute circulatory failure, where cardiac output was monitored with esophageal Doppler.

The authors quoted as background previous papers reporting end-tidal $\mathrm{CO}_{2}$ changes in animal studies and case reports in humans in the setting of cardiac arrest and cardiopulmonary resuscitation. While these reports are interesting and of some relevance, more informative systematic studies of the relationship between $\mathrm{CO}_{2}$ elimination and haemodynamic and cardiac output changes are available to support their findings quantitatively.
The authors stated that "the amount of exhaled $\mathrm{CO}_{2}$ is proportional to $\mathrm{CI}$ in stable respiratory and metabolic conditions". Breen and Isserles, using data from animal and computer models, proposed a linear but not proportional relationship [3, 4]. Weil et al. [5] in 1985 used data from an animal model to suggest a logarithmic relationship. More recently, we tested a model suggesting a simple exponential relationship between short-term relative change in $\mathrm{CO}_{2}$ elimination rate $\left(V \mathrm{CO}_{2}\right)$, which mirrors $\mathrm{EtCO}_{2}$ concentration change, and change in pulmonary blood flow. This was validated using prospective data from patients during run onto cardiopulmonary bypass and during cardiac surgery and liver transplantation, across a wide range of haemodynamic states. This relationship is based on the assumption that, when considering the mass balance relationship described by the Fick equation for lung gas exchange, both $V \mathrm{CO}_{2}$ and the arterio-venous $\mathrm{CO}_{2}$ content difference will change in response to a change in pulmonary blood flow [6]. The results in the paper by Monnet et al. are consistent with this model. A mean change in CI of $12 \%$ was accompanied by change in $\mathrm{EtCO}_{2}$ of $5 \%$ overall, and a mean change in $\mathrm{CI}$ of $33 \%$ by change in $\mathrm{EtCO}_{2}$ of $10 \%$ in responders.

These theoretical and clinical studies provide quantitative confirmation for the findings of Monnet et al. In addition, they support the authors' proposition that, in patients undergoing controlled ventilation, pulmonary $\mathrm{CO}_{2}$ elimination (using $\mathrm{EtCO}_{2}$ measurement as a surrogate) provides robust real-time tracking of significant changes in cardiac output that potentially may be used to guide haemodynamic management in perioperative and critical care patients.

Conflicts of interest Assoc. Prof. Philip Peyton is has applied as an inventor on a US Patent Application No. 12/743224: "System and method for monitoring cardiac output".

\section{References}

1. Monnet X et al (2013) End-tidal carbon dioxide is better than arterial pressure for predicting volume responsiveness by the passive leg raising test. Intensive Care Med 39:93-100. doi:10.1007/s00134012-2693-y

2. García Monge et al (2012) Non-invasive assessment of fluid responsiveness by changes in partial end-tidal $\mathrm{CO} 2$ pressure during a passive leg-raising maneuver. Ann Intensive Care 2:9

3. Isserles SA, Breen PH (1991) Can changes in end-tidal $\mathrm{PCO}_{2}$ measure changes in cardiac output? Anesth Analg 73:808-814

4. Breen PH (2010) How do changes in exhaled $\mathrm{CO}_{2}$ measure changes in cardiac output? A numerical analysis model. J Clin Monit Comput 24:413-419

5. Weil MH, Bisera J, Trevino RP, Rackow EC (1985) Cardiac output and end-tidal carbon dioxide. Crit Care Med 13:907-909

6. Peyton P (2012) Continuous minimally invasive peri-operative monitoring of cardiac output by pulmonary capnotracking: comparison with thermodilution and transesophageal echocardiography. J Clin Monit Comput 26(2):121-132

\section{P. J. Peyton (『)}

Department of Anaesthesia, Austin Health Hospital, Studley Rd Heidelberg, Melbourne, VIC 3084, Australia e-mail: phil.peyton@austin.org.au Tel.: +61-3-94963800

Fax: +61-3-9459 6421

\section{P. J. Peyton}

Department of Surgery, Austin Hospital and University of Melbourne, Melbourne, VIC, Australia 